\title{
Discussion on the Research and Development Demand and Market Benefit of Intelligent Disability Nursing Equipment - Analysis from the Perspective of Welfare Pluralism
}

\author{
Rui Xing \\ Shandong Technology and Business University, Yantai 264000, Shandong, China \\ Email: 799980825@qq.com
}

\begin{abstract}
In order to better serve the disabled, the state strongly supports the research and development and production of intelligent nursing equipment, thus ensuring and improving the quality of life and the sense of happiness of the disabled. This paper analyzes the current market situation of disabled nursing equipment and nursing products at home and abroad. Combined with the national pension and welfare policies, the paper analyzes the current market demand, market benefit and investment risks of intelligent disabled nursing equipment from the perspective of welfare pluralism, aiming at the development demand of intelligent disabled nursing equipment. This paper provides research and development suggestions and countermeasures for intelligent disability nursing equipment of Anhui Liwei Precision Machinery Co., Ltd.
\end{abstract}

Keywords: the disabled, nursing equipment, intelligent, market demand, benefits

\section{Introduction}

Along with high-speed development of the society and economy of our country, the proportion of aging population will be more and more high. To better serve the aging and the disabled, the government should improve the quality of life of the community, vigorously develop social welfare programs and community service at the same time, and encourage social forces to participate actively the investment, technology research and development of nursing equipment. To meet social and market demand, common wisdom endowment service industry ecosystem should be built. This paper reviews and summarizes the preliminary demonstration and research and development of intelligent disability nursing equipment in Anhui Liwei Precision Machinery Co., Ltd..

\section{Current market demand of intelligent disability care equipment}

\subsection{Applicable people}

Disabled children, disabled elderly, seriously ill patients and rehabilitated people. The intelligent nursing equipment developed by the company is designed for the disabled elderly (old, disease, disability and other reasons, eating, bathing, dressing, toilet, control of urine and feces, indoor activities and other daily life must be assisted by others or completely rely on the assistance of others).

\subsection{Existing products in the market}

\subsubsection{Well-known foreign manufacturers}

On century 90 time is the enlightenment development stage of intelligent nursing bed. Due to factors such as aging and labor costs, with the continuous progress of science and technology, American and Japanese companies are the first to carry out research and development in the field of intelligent nursing beds. So far, these two countries have developed the most products with the most abundant functions. Among them, and to Paramount Bed, Stryker (Stryker), Eeyore (HillROM) three company products as the representative. Its product features include highly specialized design and production, advanced technology, wide coverage of the product line, complete market segmentation standards and specifications. From the market basic categories are divided into two: one is intensive care unit (ICU) with medical care beds, suitable for professionals long time care and emergency medical treatment. This kind of nursing bed is highly technical, with complete functions, which can meet the special requirements of intensive care. It is basically fully electric, but the price is relatively high. The second is the general medical care bed, a wide range of application, can be from hospital to professional nursing institutions to family care, its product features technology and functionality is relatively low, electric manual can be, a high degree of diversification, low price. 


\subsubsection{Domestic manufacturers}

The research and development of multi-functional intelligent nursing bed in China is still in its infancy. Most of them are mainly small and medium-sized enterprises. They lack their own core technology and are limited to imitation and generation processing. The functions of the products are mostly based on daily care, such as taking the second defecation, turning over, back lifting, cleaning and other products are not rich enough in functions, which can only meet the basic needs of the elderly, and cannot further improve their quality of life. Domestic representative companies include small cotton-padded jacket Chuangmingli, Pukang and so on.

\subsubsection{Competitive positioning}

Foreign intelligence nursing bed technology advanced, the function is all ready, domestic existing import a combined with institutions use individual demonstration type, but because of a lack of based on Internet of things, cloud computing, big data the wisdom of the medical service management platform, to further implement, such as the patient's vital signs parameters and the connectivity of medical institutions information intelligent function has been a great challenge, and domestic intelligence nursing bed function relatively single, technical force is weak, and is for the small and medium-sized enterprises. Building the intelligent multi-functional nursing bed care management system platform will be a revolution in the field of intelligent medical care, aiming to build the ecosystem of intelligent elderly care service industry, which is highly consistent with the national development action plan of intelligent health care industry, and has an irreproducible technological core and differentiated competitive advantages.

\subsection{Market demand}

After being incapacitated in bed, the elderly cannot take care of themselves, and must rely on others to provide longterm care, including medical treatment, life help and psychological and spiritual consolation. The burden of the family is increased, the burden of the social old-age security system is heavy, and the national financial expenditure is large.

China's sixth national population census; $81 \%$ of the non-disabled elderly and $19 \%$ of the disabled elderly. There are more than 200 million people aged 60 or above, accounting for $13.26 \%$ of the total population in China.In China, the disabled elderly reached 33 million, accounting for $19 \%$ of the elderly population (data source: the sixth national census). As can be seen from this, the market demand for intelligent disabled nursing equipment is huge.

\subsubsection{Current situation of aging}

China's pension situation is grim. It is estimated that by 2020 , the elderly population over 60 will increase to about 255 million, accounting for about $17.8 \%$ of the total population. The number of elderly people will rise to about 29 million, and the number of elderly people living alone or empty-nesters will rise to about 118 million, and the old-age dependency ratio will rise to about $28 \%$. Social security spending on the elderly will continue to rise; The actual aging of rural resident population may be further deepened. The number of disabled elderly people is also expected to grow at an estimated rate, so the market demand for intelligent care devices will grow.

\subsubsection{Responsibility requirements of enterprises from the perspective of welfare pluralism}

Welfare pluralism advocates that the government is no longer the only provider of social welfare, and social enterprises should also contribute to the national social welfare. The company's research and development of intelligent nursing equipment actively responds to the national call and conforms to the development of The Times. Undertaking development, the CPC Central Committee and state council attaches great importance to and development of the pension system, to implement "much starker choices-and graver consequences-in" national undertaking development, and development of the pension system planning is to carry out the party central committee and state council on coping with an ageing population policy decisions of the important measures, to safeguard and improve people's livelihood, enhance the old people engaged and feeling and happiness, realize the goal of struggle to build a well-off society in an all-round way has important strategic significance.

\subsubsection{Market demand positioning}

To improve the disability, half disability elderly chronic disease or physical disabilities, disabling the patient's quality of life, auxiliary its recovery, reduce dependence on nurses' completely, the spirit of the children of the patient's family, to reduce the economic burden, intelligent multi-function nursing bed care management system platform, overturns the traditional mode of care, reshape the existing ecological chain of care, to provide users with the standing postures, a full range of intelligent service and perfect, comfortable experience of application of can be widely used in home endowment and community endowment, combined hospital, medical institutions, and the scene. 


\section{Market benefit analysis of intelligent disability care equipment}

\subsection{Analysis of market prospects}

\subsubsection{Degree of demand of target customers}

With the improvement of the domestic economic level, consumers' demand for intelligent nursing beds continues to grow. In 2014, the demand for electric nursing beds in China was about 141,400, which increased to 275,300 in 2019. The demand of electric nursing beds in China in recent years is shown in Figure 1 and Figure 2. (source: Zhiyan Research Consulting).

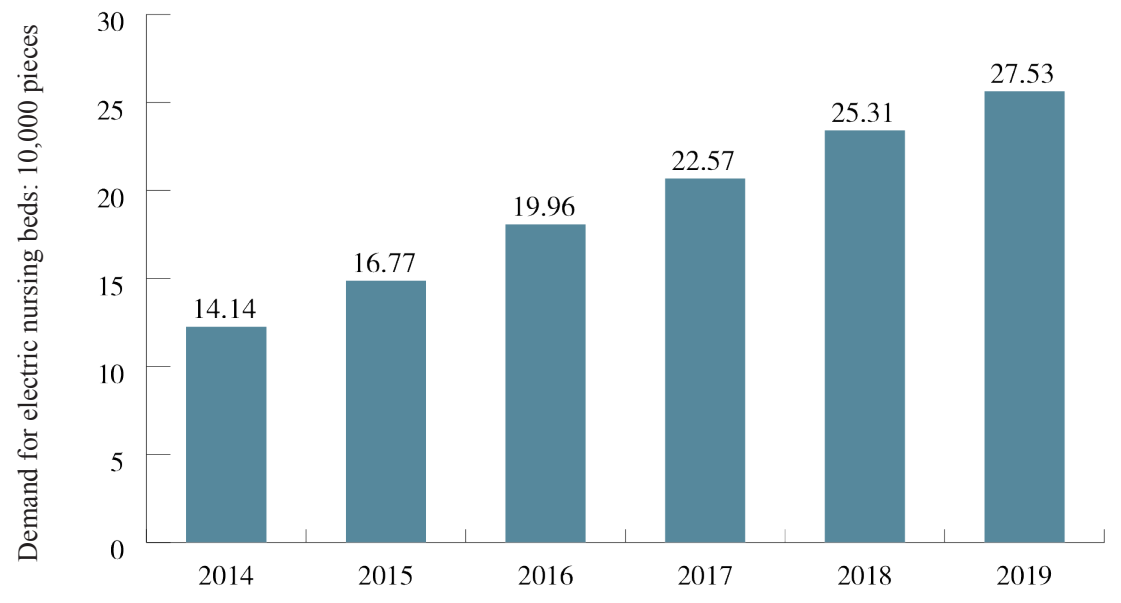

Figure 1. Demand of electric nursing beds in China from 2014 to 2019

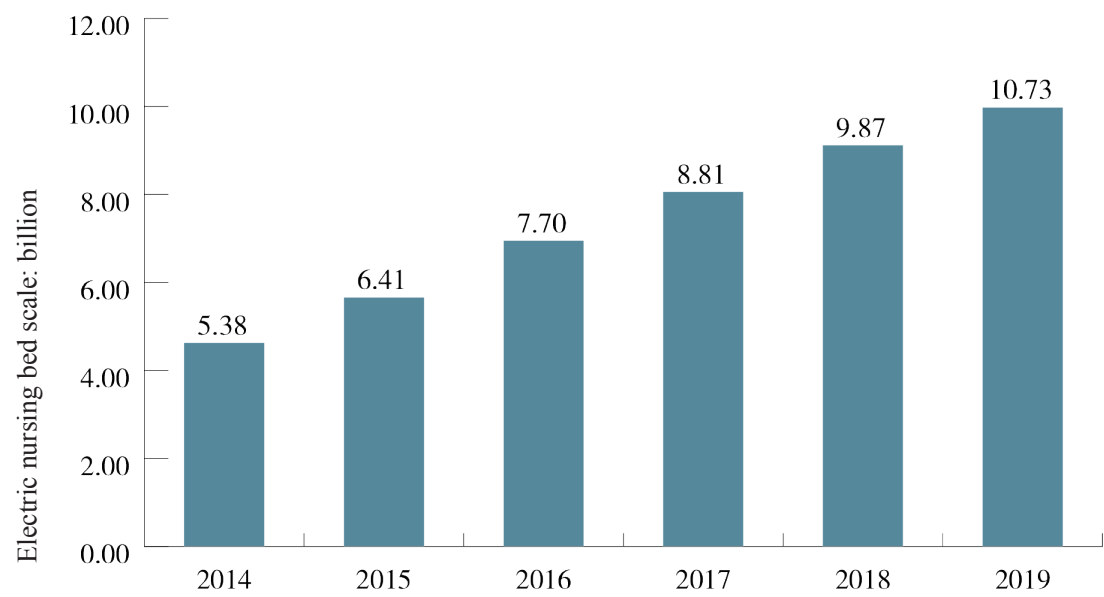

Figure 2. Trend of market size of electric nursing beds in China from 2014 to 2019

\subsubsection{Acceptance and willingness to use the product}

Under the existing community services, 37.6 percent of the elderly need cleaning, 29.1 percent need accompanying for medical treatment, and 19.9 percent need rehabilitation training. Compared with the community, the elderly living in nursing institutions still need rehabilitation training (42.4\%), emergency assistance (14.4\%), bath assistance (12.9\%), bedsore care (12.1\%), etc. (See Table 1 for more information). It can be seen that this smart bed can replace the institutions to achieve $88 \%$ of the functions.

Table 1. The future sales statistics of electric nursing beds

\begin{tabular}{cccc}
\hline Project & 2021 & 2022 & 2023 \\
\hline Sales volume (set) & 5000 & 10000 & 15000 \\
Operating income (10000 yuan) & 9000 & 18000 & 27000 \\
Net profit (ten thousand yuan) & 1350 & 2860 & 4860 \\
\hline
\end{tabular}


Therefore, the degree of willingness to use is relatively high in the survey process, which is roughly consistent with the degree of willingness to use the company's products of disabled elderly people in the questionnaire analysis.

\subsection{Cost-benefit analysis}

See Table 2 for details.

Table 2. The cost-benefit analysis

\begin{tabular}{|c|c|c|c|c|}
\hline The serial number & Project & In 2021 , & In 2022 , & In 2023, \\
\hline 2 & Operating Income (ten thousand Yuan) & 9000 & 18000 & 27000 \\
\hline 3 & Net profit (ten thousand Yuan) & 1350 & 2860 & 4860 \\
\hline
\end{tabular}

\subsection{Investment risk analysis and countermeasures}

See Table 3 for details.

Table 3. The investment risk analysis and countermeasures

\begin{tabular}{|c|c|c|c|c|}
\hline $\begin{array}{l}\text { The } \\
\text { serial } \\
\text { number }\end{array}$ & $\begin{array}{c}\text { Risk } \\
\text { categories }\end{array}$ & Content of the risk & $\begin{array}{l}\text { The risk } \\
\text { occurrence } \\
\text { possibility }\end{array}$ & Measures to prevent risk or to reduce risk loss \\
\hline 1 & Policy risk & $\begin{array}{l}\text { How does product and } \\
\text { health data collection meet } \\
\text { the risk of compliance } \\
\text { with regulatory } \\
\text { requirements }\end{array}$ & low & $\begin{array}{l}\text { The project leading unit, the project undertaking unit and the } \\
\text { participating unit all have the relevant formal qualification or } \\
\text { production qualification, have the data collection and research } \\
\text { ability in accordance with the policies and regulations, and strictly } \\
\text { implement the relevant provisions of data collection in the project } \\
\text { task research. }\end{array}$ \\
\hline 2 & Policy risk & $\begin{array}{l}\text { How does the use of user } \\
\text { health data conform to } \\
\text { the risks specified by } \\
\text { the relevant regulatory } \\
\text { authorities }\end{array}$ & low & $\begin{array}{l}\text { The project leading unit, the project undertaking unit and the } \\
\text { participating unit strictly implemented the relevant provisions of } \\
\text { data security and privacy protection in the project task research, } \\
\text { used encryption technology to transmit data, and used desensitized } \\
\text { data to carry out research as far as possible. }\end{array}$ \\
\hline 3 & $\begin{array}{l}\text { Technical } \\
\text { risk }\end{array}$ & $\begin{array}{l}\text { Clinical risks associated } \\
\text { with postural changes } \\
\text { and assisted passive joint } \\
\text { movement of the lower } \\
\text { extremity in nursing beds }\end{array}$ & low & $\begin{array}{l}\text { Repeatedly verify and test, eliminate risk factors, improve the } \\
\text { unscientific mechanism, repeatedly test the software platform, and } \\
\text { set up danger warning and stop device. }\end{array}$ \\
\hline 4 & Market risk & $\begin{array}{l}\text { The enterprises and } \\
\text { the market have a } \\
\text { low acceptance of the } \\
\text { demonstration results, } \\
\text { technical methods and } \\
\text { normative documents } \\
\text { formed by this project }\end{array}$ & low & $\begin{array}{l}\text { The project team will establish the intelligent nursing bed industry } \\
\text { alliance, actively carry out the demonstration and application of } \\
\text { normative documents, carry out publicity, training and consulting } \\
\text { services to cultivate technical management talents, and promote the } \\
\text { standardization and standardization of related manufacturing and } \\
\text { service work. }\end{array}$ \\
\hline 5 & Policy risk & Misuse of funds & low & $\begin{array}{l}\text { In accordance with the scientific research management measures } \\
\text { and other documents to carry out unified and strict management } \\
\text { of the research funds, and carry out several rounds of training and } \\
\text { internal review and supervision }\end{array}$ \\
\hline 6 & Other & $\begin{array}{l}\text { Risk of project delays due } \\
\text { to repeated epidemics }\end{array}$ & low & $\begin{array}{l}\text { The project team should make emergency plans in advance, adopt } \\
\text { online office tools and collaboration system as far as possible to } \\
\text { organize and manage the project, fully consider the adaptability of } \\
\text { home environment in the design link of the solution, and increase } \\
\text { the manpower in the process of plan deployment to speed up the } \\
\text { progress. }\end{array}$ \\
\hline
\end{tabular}

\subsubsection{Product and health data collection compliance risks}

Anhui Liwei Seiko Machinery Co., Ltd. and Suzhou Zhongke Advanced Technology Research Institute Co., Ltd. have the relevant formal qualifications or production qualifications, have the ability to meet the policies and regulations of data collection and research, in the process of project task research strictly implement the relevant provisions of data collection.

\subsubsection{Compliance risks of user health data use}

During the research process of the project task, the relevant provisions of data security and privacy protection shall be strictly implemented, the data shall be transmitted by encryption technology, and the desensitized data shall be used for research as much as possible.

\subsubsection{Technical risks}

There may be clinical risks when the intelligent multifunctional nursing bed is used to change the body position and 
assist the passive joint movement of lower limbs. The nursing bed is verified and tested for many times to eliminate risk factors, improve the irrationality of the mechanism, test the software platform repeatedly, and set up risk early warning and self-locking device.

\subsubsection{Market risks}

Early, the market formed the project demonstration results, technical methods, normative documents acceptance may be lower, will build wisdom sports standards committee and industry alliance, to demonstrate application of the normative documents, active stable cross, training and consulting service activities, cultivating technology platform management talent, proceed with the related manufacturing and services of standardization, standardization, let customers have perfect, the application of new experience, to produce viscous and dependence on a platform service.

\section{Countermeasures and suggestions for the $R \& D$ of intelligent disability nursing equipment}

\subsection{Government policy guidance perspective}

In recent years, the state has paid more and more attention to social services for the aged. General Secretary Xi Jinping pointed out in the report of the 19th National Congress that it is a major livelihood project to actively respond to the aging of the population, build a policy system and social environment for the aged, filial piety and respect for the elderly, and strengthen the undertakings and industrial development of the aged.Since the 18th CPC National Congress,Successively introduced the country is sent [2015] no. 40 "state council on promoting action guidance for" Internet + ", do hair [2015] no. 84 the State Council on forwarding health and family planning commission and other departments of promoting health and pension service combined with the guidance of the notice, do hair [2016] 47 The General Office of the State Council about to promote and standardize health data application development guidance ", the hair [2016] 91, the State Council general office on comprehensively raise pension service quality of pension services market of several opinions, ministry of united electronic 25 [2017] the wisdom health pension industry development action plan (2017-2020) ", "" much starker choices-and graver consequences-in" national undertaking development and pension system construction plan, do hair [2019] 5, General Office of the State Council on promoting the development of the endowment service opinion "and a series of policies and measures, occupy the medical community to raise combination of pension service system construction has made remarkable achievements, It has provided strong policy support for promoting the comprehensive, coordinated and sustainable development of undertakings for the elderly and realizing the strategy of a healthy China.

\subsection{Enterprise product research and development perspective}

Product development to enhance market competitiveness and market share. The nursing bed should have six key technologies: it conforms to the principle of ergonomics, can make various posture adjustment, assist patients defecation, the human-computer interaction mode is practical, has the function of physiological parameter monitoring, and has the platform of life and entertainment.

Through the study of care management basic theory, form a multi-function nursing bed function module technology, health care data collection, analysis, early warning and comprehensive solutions, in view of the long-term disability of the patients and caregivers in bed, to reduce the workload of long-term care, individualized rehabilitation demand as the goal, set up long-term care patients in bed AI operation specification, replace nurse specialists with AI early warning and intervention techniques, implement scientific care, thus enhance the bed of life of patients with self-care ability, is advantageous to the patients with physical and mental health needs, To prevent the complications caused by pressure sores, joint and tendon contracture caused by long-term bed rest.

\subsection{Market cognition and response perspectives}

Through making 3D dynamic model diagram of intelligent nursing bed, platform service model diagram, publicity brochure, website to promote products and services, holding new product launch conference, regional potential customers' meeting, and joining relevant industry associations, the brand influence and reputation of the enterprise are constantly expanded.

Aiming at different channels of agency, direct selling, installment payment, leasing and online sales, it highly matches the interests of the company, agents, users, marketing and sales personnel and market management personnel, and makes the top-level design of the price settlement system, and formulates competitive agent strategic cooperation agreements and marketing incentive policies. 


\section{Conclusion}

Due to the increasing number of the seriously disabled and elderly in China year by year, it is found through analysis that the market demand is large, and the intelligent nursing equipment of this project is expected to have good economic benefits. On the basis of meeting the needs of the society and the market, it can actively respond to the call of the country and complete a medium and long-term profitable project of social responsibility.

\section{References}

[1] Liu Jie, Zhu Lingyun, Gou Xiangfeng. Development status and trend of multifunctional nursing bed. Medical and Health Equipment. 2019; 40(07) : 94-98+103.

[2] Zhang Yuqiong. (2017) Demand Analysis and Supply Mode Research of Intelligent Care Service for Disabled Elderly. Northwest University, Xi'an.

[3] Liang Tao. Design of quality inspection devices for disabled care equipment based on RS-485 bus. Journal of FuJian University of Technology. 2013; 11(3): 252-255. 